\title{
Manajemen Kurikulum Pendidikan Anak Usia Dini Dalam Meningkatkan Kepuasan Pelanggan Studi Kasus: Taman Kanak-Kanak Hamzanwadi Pancor 2019/2020
}

\author{
M. Rudi Gunawan Parozak ${ }^{1}$, Fadma Rosita ${ }^{2}$ \\ 12 .Program Studi Pendidikan Bahasa Indonesia, Institut Pendidikan Nusantara Global, Indonesia, \\ 83511 \\ 1udigunawanparozak@ nusantaraglobal.ac.id, ${ }^{2}$ fadmarosita@nusantaraglobal.ac.id
}

\begin{abstract}
The purpose of this research is to know how the management of early childhood curriculum in Hamzanwadi Kindergarten observed from aspects of: curriculum planning, curriculum organization, school and class level curriculum implementation, and curriculum evaluation. Know the inhibiting factors and supporting factors of the application of the curriculum. Knowing about the level of customer satisfaction as well as the results achieved by the graduates of the applied curriculum. This research uses descriptive qualitative research type, with research subjects are teacher, principal, expert staff, and parents of students Kindergarten Hamzanwadi academic year 20182019. method of data collection using observation method, interview, and documentation. The validity of data is done by using data triangulation. Data analysis techniques used in this study is data collection, data reduction, data presentation, and withdrawal and testing conclusions. The results showed that: 1) curriculum planning is done by academic creative. The academic creative team consists of teachers representing each level in each branch. The curriculum is designed based on the development of the curriculum set by the government that is the curriculum 2013. 2) organizing the curriculum is done by the government. 3) the implementation of the curriculum is done well. Teachers are very categorical in carrying out the curriculum. Teachers work together to implement school-level and class-level curricula. Implementation is on schedule and according to the curriculum. 4) curriculum evaluation has been done well. From the evaluation evaluation, there is still a need for revise or perfection of the curriculum because it is still in the 2013 curriculum trial stage. Curriculum replacement for now is not necessary. 5) the inhibiting factor in the curriculum implementation is the difficulty in presenting the media from the natural materials during learning. Characteristics of developing children make teachers difficult in conditioning the class and deliver the material. Factors supporting the implementation of the curriculum in the availability of sufficient funds, facilities and complete infrastructure, and good human resources capabilities. 6) the level of customer satisfaction in the academic year 2017/2018 has been achieved with the implementation of curriculum management at the Hamzanwadi Kindergarten.
\end{abstract}

Keywords: Curriculum Management. Education. Early childhood. Customer satisfaction.

Abstrak: Tujuan dari penelitian ini adalah Mengetahui bagaimana manajemen kurikulum anak usia dini di TK Hamzanwadi Pancor yang ditinjau dari aspek: perencanaan kurikulum, pengorganisasian kurikulum, pelaksanaan kurikulum tingkat sekolah dan tingkat kelas, dan evaluasi kurikulum. Mengetahui faktor penghambat dan faktor pendukung penerapan kurikulum. Mengetahui mengenai tingkat kepuasan pelanggan dan juga hasil yang dicapai oleh lulusan dari kurikulum yang diterapkan.Penelitian ini menggunakan jenis penelitian diskriptif kualitatif, dengan subjek penelitiannya adalah guru, kepala sekolah, staf ahli, dan walisiswa TK Hamzanwadi Pancor tahun ajaran 2018/2019. metode pengumpulan data menggunakan metode observasi, wawancara, dan dokumentasi. Keabsahan data dilakukan dengan menggunakan triangulasi data. Teknik analisis data yang digunakan dalam penelitian ini adalah pengumpulan data, reduksi data, penyajian data, dan penarikan serta pengujian kesimpulan. Hasil penelitian menunjukan bahwa: 1) perencanaan 
kurikulum dilakukan oleh tim kreatif akademik. Tim kreatif akademik terdiri dari guru-guru yang mewakili setiap jenjang. Kurikulum dirancang berdasarkan pengembangan dari kurikulum yang ditetapkan oleh pemerintah yaitu kurikulum 2013. 2) pengorganisasian kurikulum dilakukan oleh kepala sekolah. 3) pelaksanaan kurikulum dilakukan dengan baik. Guru sangat kratif dalam melaksanakan kurikulum. Guru saling bekerjasama dalam melaksanakan kurikulum tingkat sekolah dan tingkat kelas. Pelaksanaan sudah sesuai jadwal dan sesuai kurikulum. 4) evaluasi kurikulum sudah dilakukan dengan baik. Dari hasill evaluasi yang dilakukan masih perlu adanya perevisian atau penyempurnaan kurikulum yang dilakukan karena masih dalam tahap trial kurikulum 2013. penggantian kurikulum untuk saat ini tidak perlu dilakukan. 5) faktor penghambat dalam pelaksanaan kurikulum yaitu kesulitan dalam menghadirkan media dari bahan alam saat pembelajaran. Karakteristik anak yang sedang berkembang membuat guru kesulitan dalam mengkondisikan kelas dan menyampaikan materi. Faktor pendukung pelaksanaan kurikulum berupa ketersedian dana yang cukup, sararana dan prasarana yang lengkap, dan kemampuan SDM yang baik. 6) tingkat kepuasan pelangan pada tahun pelajaran 2017/2018 sudah tercapai dengan dilaksanakannya manajemen kurikulum di sekolah TK Hamzanwadi Pancor.

\section{Kata Kunci: Manajemen Kurikulum. Pendidikan. Anak Usia Dini. Kepuasan Pelanggan.}

\section{PENDAHULUAN}

Pendidikan anak usia dini tidak ditekankan semata-mata pembiasaan karakter dan nilai luhur. Akan tetapi mengenai akedemis juga perlu diajarkan. Hal ini didukung oleh sebuah fakta bahwasaanya mulai masuk pada jenjang Sekolah Dasar (SD) tidak akan diberikan pemebelajaran mengenai langkah-langkah belajar menulis, membaca dan menghitung tahap awal. Guru dan kepala sekolah bekerja sama untuk Pelaksanakan pekerjaaanya berdasarkan kurikulum yang berlaku. Kurikulum telah diatur dalam Undang-Undang NO. 20 Th. 2003

tentang Sistem Pendidikan Nasional dinyatakan bahwa Kurikulum adalah seperangkat rencana dan pengaturan mengenai tujuan, isi, dan bahan pelajaran serta cara yang digunakan sebagai pedoman penyelenggaraan kegiatan pembelajaran untuk mencapai tujuan pendidikan tertentu. Kurikulum merupakan suatu permasalahan yang kompleks. Kurikulum yang sering berganti dari waktukewaktu menimbulkan polemik tersendiri bagi pendidik. Kurikulum harus memiliki sifat yang fleksibel. Kurikulum harus sesuai dengan kemajuan zaman dan mudah diaplikasikan.

Penelitian mengenai manajemen kurikulum sangatlah penting guna mengulas dan menata kemabali tentang kurikulum sebagai acuan setiap sekolah dalam menerapkan sistem pendidikan. Setiap kurikulum yang digunakan merupakan ciri khas dari setiap sekolah yang tidak bisa kita sama ratakan. Oleh sebab itu, penelitian mengenai manajemen kurikulum ini sangat penting dilkaukan agar pembaca paham mengenai kurikulum dan sistem perencanaan dan pelaksanaan kurikulum, agar dapat dijadikan referensi dalam memilih sekolah sebagai dasar pendidikan pada saat usia dini.

Tujuan dari penelitian ini adalah agar sekolah dan tenaga pendidik dapat memahami pentingnya melakukan manajemen kurikulum. Manfaat dari penelitian ini adalah, setelah mengetahui proses manajemen kurikulum yang baik, maka sekolah akan terorganisir dan dapat mencapai visi dan misi sekolah, serta meningkatkan kepuasan terhadap pelanggan.

\section{METODE PENELITIAN}

Penelitian ini menggunakan jenis penelitian diskriptif kualitatif, dengan subjek penelitiannya adalah guru, kepala sekolah, staf ahli, dan walisiswa TK Hamzanwadi Pancor tahun ajaran 2018/2019. metode pengumpulan data menggunakan metode observasi, wawancara, dan dokumentasi. Keabsahan data dilakukan dengan menggunakan triangulasi data Untuk menguji keabsahan data dengan menggunakan tehnik trianggulasi menurut Sugiyono (2014: 397) trianggulasi diartikan sebagai tehnik pengumpulan data yang bersifat menggabungkan dari berbagai teknik 
pengumpulan data dan sumber data yang telah ada. Teknik analisis data yang digunakan dalam penelitian ini adalah pengumpulan data, reduksi data, penyajian data, dan penarikan serta pengujian kesimpulan.

\section{HASIL PENELITIAN DAN PEMBAHASAN}

Diskripsi Data; Manajemen kurikulum fullday school:

Pertama; Perencanaan kurikulum: Data yang diperoleh dengan metode wawancara mengenai perencaan kurikulum adalah sebagai berikut: perencanaan kurikulum yang dilakukan di TK Hamzanwadi dilakukan oleh tim akademik yang dipimpin oleh Kepala sekolah. Perenanaan kurikulum bersumber dari kedinasan, yang kemudian dilembangkan oleh kepala sekolah dan guru, sesuai dengan visi dan misi sekolah ini.

Kedua;Pengorganisasian kurikulum: Pengorganisasian kurikulum pada siswa dilakukan dalam tahapan pelaksanaan kurikulum. Pengorganisaian kurikulum pada sisiwa pada dasarnya adalah proses penyampaian kurikulum atau materi pembelajaran dan juga program-program yang tersusun dalam sebuah kurikulum kepada peserta didik. Kemampuan guru sangat dipertimbangkan karena guru adalah orang yang akan melaksanakan kurikulum baik tingkat sekolah maupun tingkat kelas. Dalam kurikulum tingkat kelas guru wajib mengembangkan kurikulum itu agar anak merasa lebih senang saat belajar.

Ketiga; Pelaksanaan kurikulum: Pelaksanaan kurikulum tingkat sekolah dipimpin oleh kepala sekolah dan wakil kepala sekolah. Kurikulum tingkat sekolah disusun setiap tahun yang dicetak dalam kalender akademik. Pelaksanaan kurikulum tingkat kelas berjalan sesuai dengan kurikulum yang diterapkan. Pelaksanaan kurikulum dilakukan di dalam raung kelas, dan luar kelas. Kegiatan di dalam kelas seperti diskusi, menulis, mewarnai, menggunting, dan lain sebagainyya. Kegiatan di luar kelas seperti permainan air, menanam, bersepeda, berbaris, dan lain sebagainya. Guru menaati jadwal kegiatan, dan mengajar menggunakan media pembelajaran. Pembelajaran dimulai pada pukul $07.30 \mathrm{~s} / \mathrm{d} 11.00$.

Keempat; Evaluasi kurikulum: Evaluasi dilakukan agar dapat mengetahui tingkat keberhasilan kurikulum yang digunakan. Evaluasi kurikulum dilakuakn apabila terjadi kesalahan dan kekuranga terhadap kurikulum yang digunakan. Pada penelitian ini, kurikulum yang di gunakan di TK Hamzanwadi adalah kurikulum interdependent, yang artinya adalah sekolah ini melakukan pengembangan kurikulum sendiri dengan mengacu kepada kurikulum 2013 yang telah ditetapkan oleh pemerintah. Pengembangan kurikulum yang dilakukan berdasarkan dengan visi misi dari sekolah tersebut, hal apa yang ingin dicapai, dan bagaimana cara mencapainya. Evaluasi kurikulum yang saat ini masih terus dilakukan mengingat bahwa kurikulum yang baru atau kurikulum 2013 baru mulai dilaksanakan di sekolah ini dan masih dalam tahap trial. Pada kurikulum tingkat kelas, kepala sekolah juga melakukan evaluasi secara rutin, kepala sekolah dengan wakasek melakukan supervisi terhadap pelaksanaan kurikulum tingkat kelas yaitu selama satu pekan sekali. Setiap hari sabtu wakasek melakukan pemeriksaan terhadap RKH yang disiapkan oleh guru. Evaluasi kurikulum dalam hal ini dilakuakan agar kurikulum yang diterapkan dapat dilaksanakan dengan baik, dan anak-anak dapat menerima pembelajaran dengan baik juga. Keberhasilan kurikulum dinilai dari pencapaian yang telah didapatkan oleh sisiwa. Apakah siswa dapat memenuhi kriteria yang ditetapkan dan memahami pembelajaran. Alat ukur dalam mencapai keberhasilan kurikulum berupa sakala capaian, untuk hasil akhir persemester dilai dari hasil raport siswa.

Faktor penghambat dan pendukung pelaksanaan kurikulum:

Faktor penghambat dan pendukung dapat berasal dari lingkungan internal dan eksternal sekolah. Faktor penghambat yang dihadapi dalam melaksanakan kurikulum berupa keterbatasan atau kesulitan dalam menghadirkan bahan alam seperti buahbuahan langka, buah dan pohon yang berukuran besar ke dalam kelas yang 
digunakan sebagai media pembelajaran. Faktor pendukung dalam melaksanakan kurikulum tingkat kelas adalah ketersedian dana dan kelengkapan sarpras yang dimiliki sekolah ini sehingga mempermudah guru dalam melaksanakan kurikulum. Kondisi gedung yang baik, layak, nyaman, dan aman membuat siswa lebih senang ketika berada di sekolah. Sarpras yang dimiliki oleh sekolah ini benarbenar lengkap dan tertata secara rapi. Inventaris barang pun selalu tercatat di gudang penyimpanan. Sarpras utama di kelas adalah adanya AC disetiap kelas. Buku dan mainan edukatif yang lengkap. Flash card, balok, lego, dan media peraga lainnya dimiliki oleh masing-masing kelas. Kelas dilengkapi dengan rubber yang yaman dan aman saat belajar. Buku menulis, buku menempel dan buku menggambar tersedia untuk masing-masing siswa. Setiap siswa juga memiliki loker masing-masing untuk menyimpan LKS dan peralatan mereka. Setiap sisiwa juga diberikan fasilitas berupa dayli record yang digunakan untuk berkomunikasi dengan walisisawa untuk menyampaikan kegiatan apasaja yang dialkukan dan perkembangan anak selama disekolah dan di rumah

\section{Pertama; Tingkat kepuasan} pelanggan: Berdasarkan hasil wawancara yang dilakukan oleh peneliti kepada walisiswa mengenai kepuasan pelanggan, didapatkan data bahwa tingkat kepuasan pelanggan sudah terpenuhi. Banyak walisiswa yang melakukan pembelian berulang yaitu memasukan adik atau saudara kesekolah ini karena sudah merasa percaya dan yakin akan produk yang dihasilkan. Sealain pembelian berulang, pelayangan protes atau komplain terhadap kurikulum dan pelayanan di sekolah ini sangat jarang terjadi. Komplain yang disampaiakn sebatas perkembangan anak dan kecelakaan yang dialami anak. Hal ini dapat dikatakan bahwa kepuasan pelanggan sudah tercapai. Berdasarkan hasil wawancara yang dilakaukan dengan beberapa walisiswa, komplain yang diajukan walisiswa terhadap sekolah sebenarnya beragam, rata-rata yang dikeluhkan adalah mengenai perkembangan siswa itu sendiri. Terkadang siswa di sekolah tidak mau mengikuti kegiatan menulis di sekolah, akan tetapi di rumah siswa tersebut sudah dapat menulis. Komplain yang lain meliputi jika ada kecelakaan terhadap anak, misalkan terjatuh tetapi guru tidak menyampaikan kepada orangtua siswa.

Dari data mengenai komplain yang didapat dari hasil wawancara secara nonstruktural, didapatkan hasil bahwa walisiswa tidak banyak melayangkan komplain. Beberapa walisiswa yang diwawancarai tidak pernah melayangkan komplain yang serius dan menjadi permasalahan bagi sekolah. Pelayanan yang didapatkan pelanggan sudah cukup baik dan memuaskan. Tingkat kepuasan terhadap produk dan layanan, dirasakan oleh walisiswa sudah cukup memuaskan. Beberapa walisiswa mengatakan jika pelayanan dan produk yang dihasilkan sudah sesuai harapan dan memuasakan. Saran yang diberikan oleh beberapa walisiswa rata-rata mengenai harga, penambahan kegiatan outdor dan perluasan halam untuk kegiatan agar lebih nyaman, Selain dari wawancara yang dilakukan dengan walisiswa, sekolah TK Hamzanwadi memiliki poling terhadap pelanggan dengan cara memberikan lemabar testimony kepada pelanggan dan dirangkum oleh kepala sekolah guna mendapatkan hasil apakah pelanggan merasa puas atau tidak. Komplain apa yang disampaikan sehingga sekolah dapat melakukan evaluasi terhadap pelayanan dan kinerja.

\section{Pembahasan}

Manajemen kurikulum pendidikan usia dini: Manajemen kurikulum yang dilakukan pada sekolah ini sudah baik dan sesuai dengan teori meliputi cakupan 4 bidang yaitu: perencanaan, pengorganisasian, pelaksanaan, dan evaluasi kurikulum Rusman (2012: 4). proses manajemen kurikulum yang dilakukan oleh sekolah ini sudah mencakup empat tahapan seperti yang dijelaskan pada bab sebelumnya. Manajemen kurikulum juga telah dilakukan dengan matang dan tersistem sesuai dengan teori yang disampaik oleh Rusman (2009:3). bahwasanya manajemen atau pengelolaan kurikulum harus kooperatif, komprehensif, sistemik, dan sistematik dalam rangka mewujudkan ketercapaian tujuan 
kurikulum. Manajemen kurikulum dapat dilakukan dengan baik karena ada tim khusus yang melakukan manajemen yang mencakup seluruh kebutuhan di sekolah TK Hamzanwadi.

Pertama; Faktor penghambat dan pendukung pelaksanaan kurikulum: Dari penelitian yang telah dilakukan, didapatkan hasil berupa beberapa faktor penghambat dan pendukung pelaksanaan kurikulum. Faktor penghambat yang dihadapi dalam pelaksanaan kurikulum berasal dari faktor eksternal dan faktor internal. Faktor eksternal yang menghambat guru dalam melakukan pelaksanaan kurikulum tingkat kelas adalah sulitnya mendapatkan media pembelajaran yang berasal dari bahan alam. Dari proses pelaksanaan kurikulum, hambatan eksternal yang dihadapi baru sebatas keterbatasan bahan alam yang terkadang susah untuk dihadirkan ke dalam kelas.

Faktor penghambat yang berasal dari faktor internal berasal dari siswa. Karakteristik siswa dan perkembangan sisiwa yang membuatguru terkadang sulit untuk melakukan pengondisian kelas dan menyampaikan materi. Berdasarkan hasil evaluasi yang dilakukan, terlihat anak-anak sering banyak mengobrol dan bercanda. Terkadang karena kurangnya umur anak tersebut, anak sulit mengikuti materi yang diberikan.

Faktor pendukung dari pelaksanaan kurikulum jika dilihat dari hasil observasi yang dilakukan adalah ketersediaan sarpras yang sangat mendukung pelaksanaan kurikulum. Dari keragaman media pembelajaran yang terdiri dari flash card, lem, pewarna kuarto, aneka kertas, lego, balok, komputer, internet, $L C D$ dan proyektor, peralatan ekstrakurikuler seperti alat drum band, alat tulis habis pakai, dan lain sebagainya. Keadaan kelas yang nyaman dan bersih juga mendukung pelaksanaan kurikulum.

Selain sarpras, yang lengkap dan mendukung. Faktor pendukung keterlaksanaan kurikulum yang lain adalah dari dana dan SDM dari sekolah ini. Berdasarkan dari hasil pengamatan yang telah dilaukan oleh peneliti,
SDM atau guru dan karyawan bekerja sama sehingga menjadikan pelaksanaan tidak terhambat. Komunikasi yang baik membuat pelaksaan berjalan dengan lancar. Guru terlihat cekatan dan kreatif dalam melakukan pembelajaran. Pengawasan yang ketat terhadap anak membuat anak merasa aman saat belajar.

Kedua; Tingkat kepuasan pelanggan: Hasil penelitian menunjukan bahwa, tingkat kepuasan pelanggan pada sekolah ini berupa kepuasan terhadap pelayanan dan produk yang dihasilkan. Kepuasan pelanggan jika dinilai dari tiga indikator kepuasan pelanggan yaitu: Kesesuaian kualitas pelayanan dengan tingkat harapan, tingkat kepuasan apabila dibandingkan dengan yang sejenis, tidak ada pengaduan atau komplain yang dilayangkan, maka di dapatkan hasil bahwa kepuasan pelanggan pada tahun pelajaran 2018/2019 ini sudah tercapai.

Jika dilihat dari teori indikator kepuasan pelanggan yang disampaikan oleh Yuliarmi dan Riyasa (2007) dalam penelitian yang dilakukan oleh Januar Efendi Panjaitan dan Ai Lili Yuliati dalam jurnal Jurnal Manajemen Vol. 11 No. 2, September 2016, dikatakan bahwa indikator kepuasan pelanggan adalah Kesesuaian kualitas pelayanan dengan tingkat harapan, tingkat kepuasan apabila dibandingkan dengan yang sejenis, dan tidak ada pengaduan atau komplain yang dilayangkan. Maka kepuasan pelanggan pada sekolah KB TK Primagama dapat dikatakan sudah tercapai.

Dari hasil wawancara yang dilakukan dengan walisiswa yang didukung dengan wawancara kepada manajer sekolah ini, didapatkan fakta bahwa kesesuaian produk dengan harapan sudah tercapai, jika dibandingkan dengan sekolah lain, sekolah ini lebih unggul dalam kurikulum yang diterapkan, dan adanya program-program unggulan yang diberikan kepada pelanggan. Tingkat penyampaian komplain juga tidak terlalu kompleks, hanya mengenai masalah perkembangan anak, armada untuk kegiatan out door activity, dan kecelakaan kepada anak selama di sekolah. 
Penilaian kepuasan pelanggan juga didapat dari testimony yang diberikan oleh sekolah pada setiap akhir semester dan akan dijadikan bahan evaluasi untuk memperbaiki pelayanan dan produk yang diberikan.

\section{KESIMPULAN}

Kesimpulan pada penelitian ini akan dilihat dari :

Pertama; Manajemen kurikulum Pendidikan Usia Dini: (a) Perencanaan kurikulum kurikulum Perencanaan yang telah dilakukan di sekolah ini sudah sangat baik. Perencanaan kurikulum dilakukan setiap awal tahun ajaran baru. Proses perencanaan kurikulum dilakukan dengan penuh pertimbangan dan perencanaan yang matang. Proses perencanaan kurikulum dilakuan oleh tim yang solid dan terdiri dari gabungan guruguru yang berkompeten pada bidangnya. Guru yang terpilih merupakan guru yang bertanggungjawab, loyal dan kreatif. Kurikulum yang diarancang juga tidak menyimpang dari ketentuan yang telah ditetapkan oleh pemerintah.

Pengorganisasian kurikulum berdasarkan hasil penelitian yang telah dilakuakan pada bagian pengorganssasian kurikulum, dapat ditarik kesimpulan bahwa proses pengorganisasian kurikulum telah berjalan dengan sangat baik. Hal ini dilandasi oleh faktor bahwa pemilihan SDM dalam proses pengorganisasian kurikulum dilakukan dengan sanagt teliti dan penuh pertimbangan. Pemilihan SDM dalam proses pengorganisasian ditentukan dengan melihat kompetensi yang ada pada individual SDM tersbut. Dengan adanya proses yang teliti, maka pengorganisasian kurikulum menjadi lebih tepat sasaran dan memperlancar proses pelaksanaan kurikulum pada akhirnya. (c) Pelaksanaan kurikulum dari pemaparan data dan pembahasan mengenai pelaksanaan kurikulum pada bab IV di atas, maka dapat ditarik kesimpulan bahwa pelaksanaan kurikulum juga sudah berjalan sebagai mana mestinya. Kurikulum pada tahun ajaran 2018/2019 terlaksana dengan baik dan lancar. Proses pelaksanaan kurikulum tingkat sekolah sudah terlaksana dengan baik, karena dilaksanakan oleh SDM yang berkompeten pada bidangnya. Pelaksanaan kurikulum tingkat kelas juga sudah berjalan dengan baik. Tidak ada komplain dan masalah yang yang berarti pada proses pelaksanaan kurikulum tingkat kelas. Pelaksanaan kurikulum tingkat kelas dilaksanakan dengan menggunakan metode pembelajaran corner yang sesuai dan menarik. (d) Evaluasi kurikulum dari hasil penelitian yang telah dilakukan dalam beberapa bulan terakhir mengenai evaluasi kurikulum diTK Hamzanwadi dapat ditarik kesimpulan bahwa, proses evaluasi sudah dilakukan dengan baik. Kepala sekolah dan wakasek bekerja sama dalam melakukan evaluasi mengenai pelaksanaan kurikulum dan kinerja guru. Hasil yang didapatkan dari evaluasi yang telah dilakukan adalah, kurikulum yang telah direncanakan dan dilaksanakan pada tahun pelajaran 2018/2019 sudah baik. Penyempurnaan kurikulum yang baru yaitu kurikulum 2013 masih perlu ditingkatkan agar lebih baik lagi. Untuk perubahan kurikulum, saat ini tidak perlu dilakukan, karena kurikulum yang diterapkan di sekolah ini sudah berhasil dan sudah baik.

Kedua; Faktor penghambat dan faktor pendukung pelaksanaan kurikulum dari hasil observasi yang dilakukan oleh peneliti mengenai faktor penghambat dan faktor pendukung pelaksanaan kurikulum, dapat ditarik kesimpulan bahwa, terdapat beberapa faktor pendukung dan faktor penghambat. Dari hasil analisi yang telah dilaksanakan pada bab IV, faktor penghambat yang dihadapi oleh sekolah ini sudah dapat diatasi dengan baik. Faktor pendukung yang ada di sekolah ini sangat membantu proses pelaksanaan kurikulum. Dengan adanya faktor pendukung seperti dana, sarpras, dan SDM yang berkualitas, pelaksanaan kurikulum dapat berjalan dengan baik.

Ketiga; Tingkat kepuasan pelanggan: Dari hasil penelitian yang telah dilakukan mengenai tingkat kepuasan pelanggan mengenai pelayanan dan produk yang dihasilkan dari manajemen kurikulum yang telah dilakukan oleh sekolah TK Hamzanwadi, dapat ditarik kesimpulan bahwa pelanggan sudah merasa terpuaskan dengan sistem manajemen kurikulum yang dilakukan. Jika dilihat dari tiga indikator kepuasan pelanggan 
yang telah dipaparkan pada bab III, maka kepuasan pelanggan juga sudah terpenuhi. Hasil yang dicapai selain kepuasan pelangan berupa tingkat kemandirian anak yang lebih dari sebelumnya. Kemampuan akademik juga lebih meningkat dan lebih baik.

Hal negatif yang muncul dalam penciptaan kepuasan pelanggan adalah kurang adanya pemanfaatan alumnus dalam startegi marketing dan evaluasi mengenai kepuasan pelanggan. ketika sistem perolingan SDM atau guru yang membuat pelayanan kepada pelanggan akan berbeda. Dari berbagai karakter guru yang ada, pastilah ada kecocokan dan ketidak cocokan antara guru dengan pelanggan. Hal positif atau kelebihan dalam sistem ini adalah akan adanya treatment baru kepada pelanggan yang menciptakan suasana yang fresh ketika proses pembelajaran dan pelayanan terhadap pelanggan.

\section{Ucapan Terimakasih}

Alhamdulillah wa syukurillah peneliti haturkan kepada Allah SWT yang telah memberikan rahmat dan hidayahnya sehingga tesis ini dapat selesai tepat waktu. Tidak lupa pula peneliti ucapkan terimakasih kepada:

Pertama: kepada bapak Prof. Dr. Mulyoto, M.Pd. dan bapak Dr. Mundilarno, M.Pd. selaku pembimbing yang telah dengan sabar memberikan saran dan masukan terhadap penelitian ini.

Kedua: kepada kedua orangtua yang telah memberikan dukungan penuh terhadap penulisan tesis ini.

Semoga Allah, Tuhan Yang Maha Esa memberikan kebaikan dan mendapatkan imbalan pahala dan ridho dari Allah swt.

\section{DAFTAR PUSTAKA}

Efendi Panjaitan, Januar dan Ai Lili Yuliati. 2016. Pengaruh Kualitas Pelayanan Terhadap Kepuasan Pelanggan Pada Jne Cabang Bandung: Jurnal DeReMa Jurnal Manajemen Vol. 11 No. 2, September 2016.

Hamalik,Oemar .2012. Manajemen Pengembangan Kurikulum. Bandung: PT Remaja Rosdakarya offset

Rusman. 2009. Manajemen Kurikulum. Jakarta: pt rajagrafindo persada.
Semiawan.Conny R. 2010. Metode Penelitian Kualitatif. Jakarta: Grasindo.

Sugianto.Eka. 2015. Menyusun Proposal Pendekatan Kualitatif: skripsi dan tesis. Yogyakarta: Suaka Media.

Sugiyono. 2012. Metode Penelitian Pendidikan: pendekatan kuantitatif, kualitatif, dan R\&D. Tim Pengembang MKDP. 2012. Kurikulum Dan Pembelajaran. Jakarta:Pt Rajagrafindo Persada.

Sukaya.2010. Pengembangan Kurikulum Berbasis Teknologi Informasi. Padang: Jurnal Teknologi dan Informasi Pendidikan, Volume 1 NO 1, Maret 2010.

Suyadi dan Dahlia. 2014. Implementasi Dan Inovasi Kurikulum Paud 2013. Bandung: PT Remaja Rosdakarya Offset. 